\title{
COMPOSIÇÃO QUÍMICA DA ÁGUA RESIDUAL DA AQUICULTURA (ANTES E APÓS CULTIVO COM ARTHROSPIRA PLATENSIS SP ) E EFICIÊNCIA DE REMOÇÃO DE NUTRIENTES
}

Ana Victória dos Santos Borges'; Lucas Guimarães Cardoso²; Jessica Hartwig Duarte $^{3}$; Jorge Alberto Vieira Costa ${ }^{3}$; Denilson de Jesus Assis ${ }^{3}$; Janice Izabel Druzian $^{5}$; Fabio Alexandre Chinalia ${ }^{2}$; Karina Lizzeth Pedraza Galván ${ }^{5}$.

${ }^{1}$ Escola Politécnica, Departamento de Engenharia Química, Universidade Federal da Bahia, Salvador/Bahia; ana.b@outlook.com.br

2 Instituto de Ciências da Saúde, Departamento de Biotecnologia, Universidade Federal da Bahia, Salvador/Bahia.

${ }^{3}$ Laboratório de Engenharia Bioquímica, Faculdade de Química e Engenharia de Alimentos, Universidade Federal do Rio Grande, Rio Grande.

${ }^{4}$ Escola de Arquitetura, Engenharia e Tecnologia da Informação, Universidade de Salvador, Salvador/Bahia.

${ }^{5}$ Programa de Graduação em Ciência dos Alimentos, Faculdade de Farmácia da Universidade Federal da Bahia, Salvador/Bahia.

Resumo: O objetivo foi produzir biomassa da Arthrospira Platensis pela reutilização e tratamento de águas residuárias da aquicultura. Os cultivos foram realizadas em fotobiorreatores $(1 \mathrm{~L})$ com $100 \%$ de água residual de aquicultura suplementada com T-25, T-50, T-75. O tratamento com $25 \%$ atingiu uma taxa de remoção de $94,01 \%$ (Sulfatos), 93,84\% (Fosfato), 96,77\% (Bromo), 90,00\% (COD) e significativas taxas de remoção de nitrogênio ( $\geq 80 \%$ ). Assim, o tratamento com $25 \%$ pode representar uma alternativa eficiente, barata e sustentável para o setor de aquicultura, reduzindo os impactos das descargas de efluentes.

Palavras-Chave: cianobactéria, tratamento, água residual.

\section{CHEMICAL COMPOSITION OF AQUACULTURE RESIDUAL WATER (BEFORE AND AFTER CULTIVATION WITH ARTHROSPIRA PLATENSIS SP) AND NUTRIENT REMOVAL EFFICIENCY}

Abstract: The objective was to produce Arthrospira Platensis biomass by reusing and treating aquaculture wastewater. Cultures were performed in photobioreactors (1L) with $100 \%$ of residual aquaculture water supplemented with T-25, T-50, T-75. The $25 \%$ treatment achieved a removal rate of $94.01 \%$ (Sulfates), $93.84 \%$ (Phosphate), 96.77\% (Bromine), 90.00\% (COD) and significant nitrogen removal rates ( $\geq 80 \%$ ). Thus, treatment with $25 \%$ may represent an efficient, cheap and sustainable alternative for the aquaculture sector, reducing the impacts of effluent discharges.

Keywords: cyanobacterium, treatment, wastewater. 


\section{INTRODUÇÃO}

A aquicultura intensiva utiliza grandes quantidades de água doce limpa e gera fluxos de águas residuais ricos em nutrientes que podem causar a eutrofização das águas costeiras e impactar negativamente as comunidades biológicas a jusante. $\mathrm{A}$ produção de 10,7 kg por ciclo de cultivo de tilápia (1 ciclo), por exemplo, resulta em uma água residual contendo alto conteúdo de Nitrogênio $\left(96 \mathrm{~kg} \mathrm{~N}\right.$ ciclo $\left.{ }^{-1}\right)$ e pode liberar $10,7 \mathrm{~kg}$ de $\mathrm{NH}^{4+}$ no ambiente [2]. A quantidade de fósforo usado no processo de produção de $1 \mathrm{~kg}$ de tilápia é suficiente para fertilizar $1,78 \mathrm{~m}^{2}$ de solo agrícola. 0 volume de água também é significativo, cerca de $50 \mathrm{~m}^{3} / \mathrm{kg}$ de peixe. [1-4]

O cultivo de cianobactéria é frequentemente sugerido como a melhor abordagem custo-efetiva a ser aplicada em tratamento de água residual da agricultura. O cultivo de microalgas é um processo que pode alcançar mais de $90 \%$ de remoção de nutrientes inorgânicos com a vantagem de produzir biomassa com baixo custo e alto valor agregado. [5-7]

Neste contexto, esta pesquisa visa aliar a efeito de remediação realizado pela cianobactéria Arthrospira Platensis na água residual da aquicultura, determinando quais parâmetros a mesma apresentou melhor desempenho de remoção de nutrientes.

\section{METODOLOGIA}

\section{1 Água Residual da Aquicultura, Estirpe de Algas e Meio de Cultura}

O efluente aquícola foi gentilmente cedido pela Bahia Pesca S/A, localizada na Fazenda Joanes II, em Camaçari - Bahia (Nordeste do Brasil, 1241'51"S e longitude $38^{\circ} 19^{\prime} 27^{\prime \prime W}$ ). A cepa de Arthrospira Platensis $s p$ foi isolada da Lagoa Mangueira, no sul do Brasil (latitude 32으' 05 "S e longitude 3331'57" W) e mantida em meio de Zarrouk [7]. As cianobactérias Arthrospira Platensis sp foi obtida da Coleção de Cultura do Laboratório de Engenharia Bioquímica da Universidade Federal do Rio Grande (FURG).

\subsection{Preparação do Inoculo e Fluxograma Experimental}

A água residual do cultivo de tilápia (Oreochomis niloticus) foi primeiramente suplementada com diferentes porcentagens do meio sintético de Zarrouk (ZM) $\mathrm{NaHCO}_{3}$ 16,8 g/L; $\mathrm{NaNO}_{3} 2,5 \mathrm{~g} / \mathrm{L} ; \mathrm{NaCl} 1,0 \mathrm{~g} / \mathrm{L} ; \mathrm{K}_{2} \mathrm{HPO}_{4}$ 0,5 g/L; $\mathrm{K}_{2} \mathrm{SO}_{4} 1,0 \mathrm{~g} / \mathrm{L} ;$ $\mathrm{MgSO}_{4} \cdot 7 \mathrm{H}_{2} \mathrm{O}$ 0,2 g/L; $\mathrm{CaCl}_{2} 0,031 \mathrm{~g} / \mathrm{L} ; \mathrm{Na}_{2} \mathrm{EDTA} 0,08 \mathrm{~g} / \mathrm{L} ; \mathrm{FeSO}_{4} \cdot 7 \mathrm{H}_{2} \mathrm{O}$ 0,01 $\mathrm{g} / \mathrm{L}$ [7]. Devido ao seu reconhecido equilíbrio nutricional, este meio é o comumente utilizado para o cultivo da Arthrospira Platensis sp. O experimento foi realizado em duplicata onde $25 \%$ dos constituintes do Zarrouk foram adicionados a $800 \mathrm{ml}$ de água residual 
da aquicultura (T-25). Após a suplementação, o tratamento foi inoculado com Arthrospira Platensis sp (no fim da fase exponencial).

\subsection{Desenho Experimental}

A biomassa da Arthrospira Platensis $s p$ foi obtida apartir de um tanque de pista $(210 \mathrm{~L})$ em cultura contínua (1,0 biomassa $\mathrm{g} / \mathrm{L})$ mantido com o meio Zarrouk. Os diferentes ensaios foram preparados em Erlenmeyer com volume de trabalho de $1 \mathrm{~L}$. A água residual de aquicultura foi autoclavada e $800 \mathrm{ml}$ inoculada com a Arthrospira Platensis sp em concentração de $0,3 \mathrm{~g} / \mathrm{L}$ de biomassa viva, através da centrifugação do inoculo mantido nos tanques de pista. Os experimentos seguiram a metodologia proposta por Kuo et al. (2015) e Daneshvar et al. (2018) [8,9]

O tratamento T-25 foi realizado em fotobiorreatores de $1 \mathrm{~L}$ (água de aquacultura/inóculo) e controle ao meio sintético Zarrouk. O cultivo foi realizado durante 7 dias a $30^{\circ} \mathrm{C}$ com fotoperíodo de 12 horas claro/escuro. $\mathrm{O}$ ar, filtrado com lã de vidro, foi fornecido a todas as culturas e lâmpadas tubulares fluorescentes com uma intensidade de luz de 41,6 $\mu \mathrm{mol}_{\text {photons }} \mathrm{m}^{-2} \mathrm{~s}^{-1}$ foram usadas como fonte de energia.

\subsection{Composição Química da Água Residual da Aquicultura: Antes e Após Cultivo Com Arthrospira Platensis e Eficiência de Remoção de Nutrientes}

Para a caracterização química da água antes e após o cultivo, após a separação da biomassa por centrifugação, o sobrenadante foi congelado $\left(-22{ }^{\circ} \mathrm{C}\right)$ para realização das seguintes análises: Ferro $(\mathrm{Fe})$; Magnésio $(\mathrm{Mg})$; Sódio $(\mathrm{Na})$; Chumbo (Pb); Cádmio (Cd); Níquel (Ni); Cobre ( $\mathrm{Cu}$ ); Zinco ( $\mathrm{Zn})$ e Manganês (Mn) (SM-3120 B); Salinidade, Condutividade, Alcalinidade Total e Dureza Total (SM2340 A/B/C); Sólidos Totais Dissolvidos por (SM2540 A/B), utilizando o Método Padrão para o Exame de Água e Efluentes. [10]

Os íons foram quantificados por Espectrometria de Emissão Óptica por Plasma Acoplado Indutivamente (Agilent 720/725 ICP-OES) com câmara de nebulização: Ciclônica (Single Pass); Nebulizador: SeaSpray; Potência de radiofrequência $1.10 \mathrm{~kW}$; Vazão do gás do plasma $15 \mathrm{Lmin}^{-1}$; Vazão do gás auxiliar $1,5 \mathrm{Lmin}^{-1}$; Vazão do gás de nebulização $0,75 \mathrm{Lmin}^{-1}$. Foram determinados os ânions Sulfatos, Fosfato, Bromo, Nitrogênio Nitrato, Nitrogênio Nitrito, Fluoreto e Cloretos, e os cátions Sódio $(\mathrm{Na})$, Potássio $(\mathrm{K})$, Cálcio $(\mathrm{Ca})$ e Magnésio $(\mathrm{Mg})$ segundo método proposto por Soares et al. (2015). A análise foi realizada apenas no cultivo realizado no reator tipo raceway $(5 \mathrm{~L})$.

Para o cálculo da eficiência de remoção de nutrientes, foi utilizado apenas os componentes que sofreram redução após o período de cultivo. Seguindo a Equação1 proposta por Ramsundar et al. (2017) [11] 


\section{RESULTADOS E DISCUSSÃO}

A caracterização química mostrou que a água residual de aquicultura utilizada não possui concentrações detectáveis de chumbo, cádmio, níquel e cobre pelo método empregado na análise (Tabela 1). A caracterização demonstrou ainda que altos níveis de metais pesados podem inibir fortemente a fotossíntese e outras vias metabólicas, levando a mudanças no tamanho e forma das células. [12] O acúmulo de metais pesados pode estar relacionado a corpos de polifosfato ou complexado com fitoquelatina, como observado em outras cianobactérias [16], o que pode explicar os valores relacionados à eficiência de remoção de 96,77\% do Bromo (Br). Produtos à base de $\mathrm{Br}$ podem ser usados no tratamento de problemas de saúde, como naproxeno, anti-histamínicos, anticâncer, anti-Alzheimer, anti-sépticos, narcóticos.[13,14]

As águas residuais apresentaram níveis significativos de nitratos em vez de amônio. Isto indica altos níveis de oxigenação da água durante o processo de aquicultura. O tratamento T-25 mostrou significativas taxas de remoção de nitrogênio, fósforo e enxofre $(\geq 80 \%)$. As taxas de remoção de nutrientes de algas em águas residuais são frequentemente superiores a 90\%. [15] As microalgas são microrganismos conhecidos pela remoção de formas inorgânicas nitrogenadas ( $\mathrm{NO}^{-2}$ , $\mathrm{NO}^{-3}$ e $\mathrm{NH}^{+4}$ ) e orgânicas (Ureia, $\mathrm{CH}_{4} \mathrm{~N}_{2} \mathrm{O}$ ) das águas residuais. As microalgas utilizam $\mathrm{NO}^{-3}$ após a sua redução para $\mathrm{NO}^{-2}$ e depois para $\mathrm{NH}^{+4}$ pelas enzimas nitrato e nitrito redutase [7]. Isso explica as altas taxas de remoção de Nitrato (72,11\%) e Nitrito (79,28\%). Malibari et al. (2018) encontraram um valor de nitrito de $28,7 \mathrm{mg} / \mathrm{L}$ na água residual do cultivo de camarão resultante da decomposição de rações residuais ou excreções de camarões. [16]

Tabela 1. Composição química e eficiência de remoção de nutrientes do tratamento T-25 (100\% água residual aquícola suplementada com 25\% de Zarrouk) antes e após o cultivo com Arthrospira Platensis

\begin{tabular}{ccccc}
\hline $\mathbf{N}^{\mathbf{o}}$ & Componente & $\begin{array}{c}\mathbf{T}-25 \\
(\mathbf{m g} / \mathbf{L})\end{array}$ & $\begin{array}{c}\text { Após } \\
\text { cultivo } \\
(\mathbf{m g} / \mathbf{L})\end{array}$ & $\begin{array}{c}\text { Eficiência } \\
\text { de remoção } \\
(\mathbf{\%})\end{array}$ \\
\hline 1 & Chumbo $(\mathrm{Pb})$ & $<0,03$ & $<0,03$ & - \\
2 & Cádmio $(\mathrm{Cd})$ & $<0,02$ & $<0,02$ & - \\
3 & Níquel $(\mathrm{Ni})$ & $<0,01$ & $<0,01$ & - \\
4 & Cobre $(\mathrm{Cu})$ & $<0,25$ & $<0,25$ & - \\
5 & Manganês $(\mathrm{Mn})$ & $<0,01$ & $<0,01$ & - \\
6 & Zinco (Zn) & $<0,01$ & $<0,01$ & - \\
7 & Fluoreto & $<0,25$ & $<0,25$ & - \\
8 & Nitrogênio Nitrato & $18,65 \pm 0,01^{\mathrm{a}}$ & $5,20 \pm 0,01^{\mathrm{b}}$ & 72,11
\end{tabular}


9

10

11

12

13

14

15
Nitrogênio Nitrito

$\left(\mathrm{NO}^{-2}\right)$

DQO

Sulfatos

Fosfato

Bromo (Br)

Amônia
$10,33 \pm 0,05^{\mathrm{a}}$

$2,14 \pm 0,03^{b}$

$300 \pm 0,03^{\mathrm{a}}$

$30 \pm 0,12^{\mathrm{a}}$

$27,54 \pm 0,01^{\mathrm{b}}$

$1,65 \pm 0,04^{\mathrm{a}}$

$11,37 \pm 0,02^{\mathrm{b}}$

$0,70 \pm 0,02^{\mathrm{a}}$

$<0,01^{\mathrm{a}}$

$<0,25$

$<0,25$

$0,03 \pm 0,06^{\mathrm{a}}$
79,28

90,00

94,00

93,84

96,77

72,72

As águas residuais da aquicultura contêm quantidades significativas de produtos orgânicos. A demanda química de oxigênio (DQO) média para esse tipo de efluente é de cerca de $300 \mathrm{mgL}^{-1}$. A DQO é frequentemente resultante de uma mistura de proteínas (40 a 60\%), carboidratos (25 a 50\%) e lipídios (8 a 12\%) nas águas residuais da aquicultura [17]. A Tabela 2 mostra que a remoção de DQO do tratamento T-25 estava acima de $90 \%$. Assim, a cinética de crescimento e aeração média da Arthrospira Platensis $s p$ durante o cultivo criaram um ambiente favorável para a biodegradação de compostos orgânicos. Há alguns relatos de que Arthrospira Platensis sp também pode crescer mixotroficamente [17]. Este tipo de crescimento de algas é frequentemente sustentado por pequenos compostos orgânicos, como glicose, acetato ou glicerol. Estes são compostos que podem potencialmente aparecer durante a biodegradação de compostos orgânicos de águas residuais de aquicultura. No entanto, este não foi o objeto de estudo desta pesquisa.

Desta forma, a produção de biomassa da cianobactéria a partir de águas residuais da aquicultura é uma solução possível para a necessidade urgente de um alimento vivo na aquicultura. Além disso, a bioprospecção de microalgas capazes de crescer em águas residuais de aquicultura modificadas pode abrir caminho para a comercialização no próprio setor da aquicultura e diminuir a liberação de efluentes, uma vez que a aquicultura intensiva para produzir $1000 \mathrm{~kg}$ de peixe, utiliza cerca de $8,4 \mathrm{~m}^{3} \mathrm{t}^{-1}$ de água limpa [3].

Alva et al. (2018) avaliaram o crescimento de Dunaliella sp., Nannochloropsis sp. e Tetraselmis sp. em água residual da maricultura as três espécies de microalgas foram capazes de remover $>90 \%$ de nitrogênio e ortofosfatos e $80 \%$ de carbono. Para Spirulina platensis, Markou et al. (2012) relataram remoção de $73 \%$ da $\mathrm{DQO}$ inicial, enquanto $\mathrm{Pe} \mathrm{NO}^{-3}$ foram totalmente removidos das águas residuais da fábrica de azeite. Também foram estudados água residual da criação aves como parte do meio de cultivo para o cultivo de $S$. platensis e $C$. vulgaris apresentando > 99\% de remoção do $\mathrm{PO}^{-4}$. [18-20]

\section{CONCLUSÃO}

Os melhores resultados foram obtidos usando $25 \%$ dos ingredientes gerais descritos no meio sintético Zarrouk. Em tal tratamento, foram observados elevados índices de eficiência de remoção de nutrientes. Assim, a Arthrospira platensis sp. 
cultivada em água residual do cultivo de Oreochomis niloticus suplementado com $25 \%$ de Zarrouk, pode representar uma alternativa sustentável para melhorar as condições ambientais da prática aquícola, reduzindo os impactos das descargas de águas residuais.

\section{Agradecimentos}

Todos os autores agradecem o apoio da FAPESB - Fundação de Amparo à Pesquisa da Bahia no projeto CNPQ (400710 / 2014-5), MCTIC (Ministério da Ciência e Tecnologia da Informação e Comunicação) - Brasil e Bahia Pesca.

\section{REFERÊNCIAS}

1 Wuang, S. C. Khin, M. C. Chua, P. Q. D. Luo, Y. D. (2016). Use of Spirulina biomass produced from treatment of aquaculture wastewater as agricultural fertilizers. Algal Res, 15, 59-64.

2 Ferreira, J. G. L. Falconer, J. Kittiwanich, L. Ross, C. Saurel, K. Wellman, C. B. Z. P. Suvanacha. (2015). Analysis of production and environmental effects of Nile tilapia and white shrimp culture in Thailand. Aquac. Res 447, 23-36.

3 Samuel-Fitwi, B. Sven Wuertz, J. P. Schroeder, C. S. (2012). Sustainability assessment tools to support aquaculture development. Aquac. Res. 32, 183-192.

4 Martins, A. P. Zambotti-Villela, L. Yokoya, N. S. Colepicol, P. (2018). Biotechnological potential of benthic marine algae collected along the Brazilian coast. Algal Res, 33, 316-327.

5 Huang, Y. Chen, Y. Xie, J. L. Huacai, W.C. (2016). Bio-oil production from hydrothermal liquefaction of high-protein high-ash microalgae including wild Cyanobacteria sp. and cultivated Bacillariophyta sp. Fuel, 183, 9-19.

${ }^{6}$ Kuo, C. Chen, T. Lin, T. Kao, C. Lai, J. Chang, J. Lin, C. (2015). Cultivation of Chlorella sp., GD using piggery wastewater for biomass and lipid production. Bioresour. Technol, 194, 326-333.

7 Salama, E. Byong-Hun, J. B. Chang, W. S. Lee, S. Roh, H. Yang, I. (2017). Interactive effect of indole-3-acetic acid and diethyl aminoethyl hexanoate on the growth and fatty acid content of some microalgae for biodiesel production. J. Clean. Prod, 168, 1017-1024.

${ }^{7}$ Costa, J.A.V. Colla, L.M. Duarte Filho, P. Kabke, K. Weber, A. (2004). Modelling of Spirulina platensis growth in fresh water using response surface methodology. World $\mathrm{J}$ Ind Microbiol Biotechnol , 18, 603-607.

${ }^{8}$ Kuo, C. Chen, T. Lin, T. Kao, C. Lai, J. Chang, J. Lin, C. (2015). Cultivation of Chlorella sp., GD using piggery wastewater for biomass and lipid production. Bioresour. Technol, 194, 326-333. 
9 Daneshvar, E. Antikainen, L. Koutrac, E. Kornarosc, M. Bhatnagara, A. (2018). Investigation on the feasibility of Chlorella vulgaris cultivation in a mixture of pulp and aquaculture effluents: Treatment of wastewater and lipid extraction. Bioresour. Technol, 255, 104-110.

10 American Public Health Association. Standard Methods for the Examination of Water and Wastewater. 21 ed. Washington: APHA, 2005.

${ }^{11}$ Ramsundar, P. Abhishek G, Singh P. Pillay, K. Bux, F. (2017). Evaluation of wate activated sludge as a potential nutrient source for cultivation of Chlorella sorokiniana. Algal Res, 28,108-117.

12 Muñoz, R. Guieysse, B. (2006). Algal-bacterial processes for the treatment of hazardous contaminants: A review. Water Res, 40, $2799-2815$.

13 Jiang, Y. Zhu, Z. Hu, A. Lei, J. (2016). Wang Towards elucidation of the toxic mechanism of copper on the model green alga Chlamydomonas reinhardtii. Ecot, 25, 1417-1425.

${ }^{14}$ Cruz, J.C.S. Iorio, M. Monciardini, P. Simone, M. Brunati, C. Gaspari, E. Maffioli S.I. Wellington, E. Sosio, M. Donadio. S. (2015). Microalgae for phosphorus removal and biomass production: a six species screen for dual-purpose organisms. J N Prod, 78, 2642-2647.

15 Guo, Z. Liu, Y. Guo, H. Yan, S. Mu, J. (2013). Microalgae cultivation using an aquaculture wastewater as growth medium for biomass and biofuel production. Int. J. Environ. Sci, 25, 85-88.

${ }^{16}$ Malibari, R. Sayegh, F. Elazzazy, A.M. Baeshen, M.N. Dourou, M. Aggelis, G. (2018). Reuse of shrimp farm wastewater as growth medium for marine microalgae isolated from Red Sea e Jeddah. J. Clean. Prod, 198, 160-169.

${ }^{17}$ Luo, Y. Le-Clech, P. Henderson, R. K. (2017). Simultaneous microalgae cultivation and wastewater treatment in submerged membrane photobioreactors: A review. Algal Res, 24, 425-437

18 Alva, M. S. Pabella, V.M.L. Ledesm, M. T. O. Gómez, M. J. C. (2018). Carbon, nitrogen, and phosphorus removal, and lipid production by three saline microalgae grown in synthetic wastewater irradiated with different photon fluxes. Algal Res, 34, 97-103.

19 Markou, G. Chatzipavlidis, I. Georgakakis, D. (2012). Cultivation of Arthrospira (Spirulina platensis) in olive-oil mill wastewater treated with sodium hypochlorite. Bioresour. Technol, 112, 234-241.

$20 \mathrm{Ji}$, Y. Hu, W. Li, X. Ma, G. Song, M. Pei, H. (2014). Mixotrophic growth and biochemical analysis of Chlorella vulgaris cultivated with diluted monosodium glutamate wastewater. Bioresour. Technol, 152, 471-476. 